Article

\title{
Performance Analysis and Optimization of Central Receiver Solar Thermal Power Plants for Utility Scale Power Generation
}

\author{
Praveen R. P. \\ Department of Electrical Engineering, College of Engineering, Majmaah University, Majmaah 11952, \\ Saudi Arabia; praveen.r@mu.edu.sa; Tel.: +966-559851412
}

Received: 23 November 2019; Accepted: 20 December 2019; Published: 23 December 2019

\begin{abstract}
The paper puts forth the design, performance analysis, and optimization of a $100 \mathrm{MWe}$ central receiver solar thermal power plant with thermal energy storage capability, which can be utilized effectively to meet the renewable energy targets of the Kingdom of Saudi Arabia (KSA). In this paper, three representative sites in KSA are selected for analysis as these sites experience an annual average direct normal irradiance (DNI) of more than $5.5 \mathrm{kWh} / \mathrm{m}^{2} /$ day. The optimization approach presented in this work aims to arrive at the best possible design parameters that suit a particular location in accordance with its DNI profile. From the analysis, an annual energy of $559.61 \mathrm{GWh}$ can be generated in Yanbu with eight hours of thermal energy storage, 18.19\% plant efficiency, and a capacity factor of $61.1 \%$. The central receiver plant in Abha would be able to offer an annual energy of 536.31 GWh with the highest plant efficiency of $18.97 \%$ and a capacity factor of $60.7 \%$. The performance of the proposed design in the two locations of Yanbu and Abha fares better when compared to the operational plant data of central receiver plant in Crescent Dunes. Based on the findings, the proposed 100 MWe central receiver Solar thermal power plants can be effectively implemented in KSA to meet the energy demands of the region.
\end{abstract}

Keywords: central receiver plant; optimization; plant efficiency; capacity factor; annual energy; LCOE

\section{Introduction}

The world's total energy demand could increase by $50 \%$ or higher by 2030 . To address tomorrow's energy demands, secure, sustainable, and cost-effective carbon-free energy production is imperative. The rise in the energy demand due to the growing population and economy cannot be met by resorting to conventional energy sources such as fossil fuels or nuclear power. As per the Paris agreement, most of the world's countries are committed to reducing carbon emissions so as to limit the global average temperature rise to well below $2{ }^{\circ} \mathrm{C}$. Renewables in the global energy mix stand at $26 \%$ in the year 2018 and they have to reach $50 \%$ by 2030 according to the Sustainable Development Scenario (SDS) of the International Energy Agency (IEA) [1].

The Kingdom of Saudi Arabia (KSA), as of 2018, has achieved only 147 MW of renewable energy (RE) capacity compared to the $2330.73 \mathrm{GW}$ capacity of the rest of the world [2]. Therefore, it is prudent for the policy makers to accelerate the prospects of harnessing energy from the abundant RE resources in the region. For KSA, solar energy is the best option for harnessing RE as the country receives over $2000 \mathrm{kWh} / \mathrm{m}^{2} /$ year in most locations [3]. The energy consumption of KSA is expected to increase three-fold by 2030, and there is an immediate requirement to harness electrical energy from the abundant renewable energy sources in the Kingdom. From statistics for the past 10 years, it is observed that the energy demand in the Kingdom is growing at a rate of eight percent with a substantial increase in demand from the housing, sector which accounts for 50 percent of the Kingdom's total electricity 
production. According to the Vision 2030 plan, KSA has announced plans to generate $9.5 \mathrm{GW}$ of electricity from renewable sources by 2030, and the government aims to invest more than 109 billion USD in the solar energy sector. In continuance with the Vision 2030 plan, and to meet the energy challenges of tomorrow, King Abdullah City for Atomic and Renewable Energy (K.A.CARE) has set its target to install $54 \mathrm{GW}$ of power from RE sources by 2032. Interestingly, the major share $(25 \mathrm{GW})$ of this target is expected to come from concentrated solar power (CSP), and the rest, $16 \mathrm{GW}$, from photovoltaic (PV) systems that directly convert solar energy to electrical energy. Presently, the total installed solar energy capacity of Saudi Arabia is only 139 MW, of which 89 MW is generated from PV technology and $50 \mathrm{MW}$ from CSP systems [2]. The research work will support the policy makers in identifying the potential sites across the Kingdom for the installation of central receiver (also called solar tower or power tower) plants, which is a type of CSP plant wherein an array of dual-axis tracking reflectors (heliostats) concentrates sunlight on a tower-mounted receiver that contains heat transfer fluid (HTF). The HTF can be heated to $500-1000{ }^{\circ} \mathrm{C}$, which can be then used as a heat source for power generation. Stand-alone renewable energy plants have challenges to deliver stable power to the grid. These plants require backup support in terms of electrical or thermal energy storage to supply firm power. The electrical storage requires large capital outlay and maintenance. Although the capital cost for PV systems is lower than that of CSP systems, the former accounts for a higher cost of power generation when taking into account the aspects of energy storage and power stability. CSP with thermal energy storage offers lower energy generation costs compared to PV with electrical energy storage to provide stable dispatchable power at large-scale plant capacities.

Solar thermal power plants are ideal for locations that offer high direct normal irradiance (DNI), preferably in the range of $2000 \mathrm{kWh} / \mathrm{m}^{2}$ to $2500 \mathrm{kWh} / \mathrm{m}^{2}$. The data from K.A.CARE indicate that most of the provinces in KSA offer high DNI and, hence, are suitable for the installation of CSP plants. There are four types of CSP technologies: Parabolic trough collector, central receiver, linear fresnel reflector, and parabolic dish systems. Among these technologies, parabolic trough collector and central receiver plants are most popular for utility scale power generation.

Among the CSP technologies mentioned above, solar power tower or central receiver-based CSP technology is projected to be cheaper by 2020 [4]. They are gaining popularity when compared to parabolic trough systems due to their ability to operate at higher HTF temperature, thereby substantially bringing down the thermal energy storage (TES) costs. In addition, the land requirement for the solar tower-based CSP system is small when compared with other technologies. In this research work, a solar tower-based CSP system was designed and analysed so as to be installed in potential locations in the Kingdom of Saudi Arabia.

Figure 1 shows the working of a central receiver solar thermal power plant, which mainly includes three sub systems: Heliostat field, the central receiver, and power conversion system. Central receiver plants use point focus technology where a heliostat field consisting of a number of flat movable mirrors focuses the sunlight on to a receiver mounted on top of a tower. The HTF circulated in the central receiver absorbs the heat from the solar rays reflected by the heliostats.

By using appropriate HTFs, a working temperature of even $1000{ }^{\circ} \mathrm{C}$ can be achieved, improving power cycle efficiency. A power conversion system employing the Rankine cycle then coverts the thermal energy absorbed by HTF into electrical energy. One of the main highlights of solar tower-based technology when compared to other CSP-based technologies is that by using appropriate HTF, temperature of even $1000{ }^{\circ} \mathrm{C}$ can be reached, which improves the power cycle efficiency.

The main aim of this research work is to put forth an improved modeling and optimization approach that can be adopted for sizing the central receiver plants for any potential locations around the world. Most of the regions in the GCC (Gulf Cooperation Council) are considered ideal for the installation of CSP plants as their annual average direct normal irradiance (DNI) is greater than $5.5 \mathrm{kWh} / \mathrm{m}^{2} /$ day. However, the potential of solar thermal energy in the region has not been tapped much when compared to that of PV plants, as is clear from the projected and ongoing project details in the region. Hence, this research work also explores the viability and potential of central receiver plants 
in KSA, which can be a good indicator to the policy makers for ensuring a sustainable energy future of the GCC region.

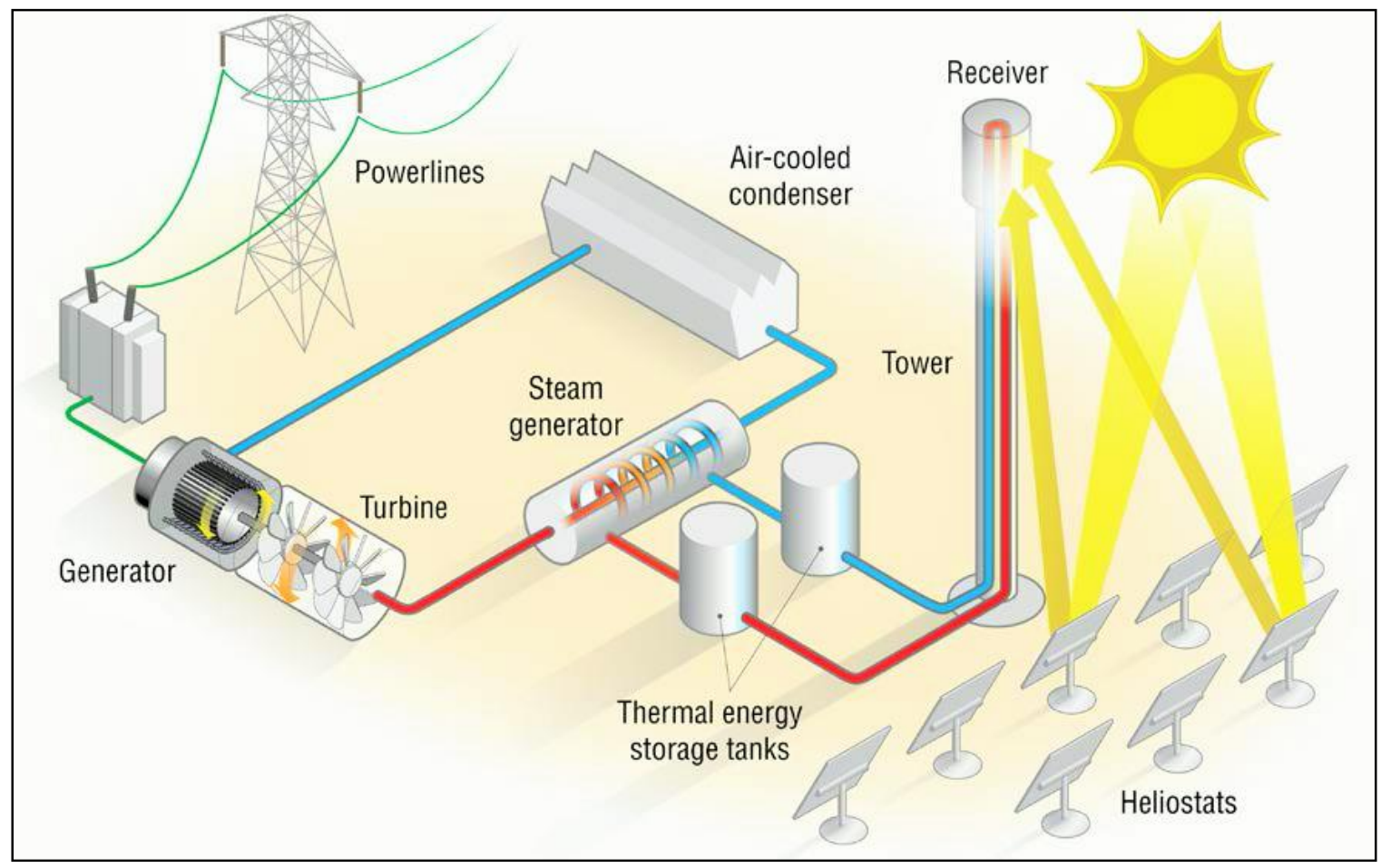

Figure 1. Working of central receiver solar thermal power plant [5].

\section{Literature Review}

The total capacity of CSP-based commercially operating projects around the world as of 2018 is $5.469 \mathrm{GW}$, and for the Middle East, it is only $156 \mathrm{MW}$ [2]. In [4], the authors reviewed the technological trends and emerging technologies in central receiver systems to operate at temperatures greater than $700{ }^{\circ} \mathrm{C}$ so as to achieve higher efficiency. The prospects of gas- and liquid-based receiver systems that can achieve this high range of operating temperatures has also been reviewed. The authors of [6] carried out a comparative analysis between the different software tools used for heliostat field design and analysis. The paper concluded that SolTrace, Tonatiuh, CRS4-2, and MATLAB code yielded similar results. Parametric analysis of medium- to large-size central receiver plants is explored in [7]. The authors studied the performance of the plants in three different locations, i.e., Seville, Daggett, and Carnarvon. The performance of the central receiver plants when subjected to direct steam and molten salt configuration, with and without thermal energy storage and different turbine capacities, was investigated. In [8], a preliminary heliostatic field layout in Southern Tunisia was carried out by reducing the optical losses due to blocking and shading effects. A nonlinear mathematical model was developed for central receiver plants using thermal energy storage in [9], and numerical optimization techniques were used to solve the model. The research work presented in [10] proposed an optimization technique for central receiver systems where heliostats' location and design of solar towers were considered simultaneously for a fixed heliostat size. The authors in [11] developed a model for the collector and receiver system of a 1 MWe Dahan solar tower plant. The authors used a STAR-90 simulation platform to evaluate the dynamic characteristics of the plant. The GEMASOLAR solar tower plant behavior in select locations of China was evaluated in [12]. The authors, based on their analysis, recommended the installation of central receiver plants in Chinese locations as it is possible to achieve annual overall efficiency of $14 \%$. The common model equations used for approximating atmospheric extinction used in ray tracing tools were summarized and compared in [13]. In [14], the authors evaluated the influence of operating strategy on the system design of CSP 
plants. The authors concluded that optimal control techniques when applied to thermal energy storage operation could improve the profitability of the plant. The potential of solar and wind energy-based distributed generation in Saudi Arabia was evaluated in [5]. The authors, based on detailed analysis, concluded that Saudi Arabia has large potential to tap renewable energy from its abundant solar and wind energy resources.

\section{Selecting the Site and Assessing the Solar Resource}

After shortlisting potential locations in the Kingdom based on the solar irradiance data, an initial design for the proposed solar tower-based CSP system was developed adhering to the specific needs of the shortlisted sites. The initial design developed was analysed in commercial software, Solar Advisor Model (SAM [15]) from National Renewable Energy Laboratory (NREL), to assess the performance of the initial design. The next stage in the research was to further optimize the initial design of the solar tower-based CSP system, and detailed analysis of the optimized design was carried out in SAM so as to give the final recommendations of the research.

Selecting an ideal site for the installation of a CSP plant is crucial for reaping maximum performance from the plant. CSP plants are economically viable to install at locations whose DNI is greater than $5.5 \mathrm{kWh} / \mathrm{m}^{2} /$ day $\left(1800 \mathrm{kWh} / \mathrm{m}^{2} /\right.$ year $)$ [16]. The data from K.A.CARE indicate that the annual average daily global horizontal irradiance (GHI) measured for the 30 weather stations spread across the Kingdom ranged from about $5.7 \mathrm{kWh} / \mathrm{m}^{2}$ to $6.7 \mathrm{kWh} / \mathrm{m}^{2}$. Hence, it is clear that there is enormous potential for solar energy-based systems in the Kingdom. On analyzing the DNI profile from K.A.CARE, the western province of Saudi Arabia has tremendous potential for CSP system installation, followed by the southern and central provinces. In this research work, three representative sites located in different provinces of Saudi Arabia, i.e., Yanbu in the Western province, Abha in the southern province, and Dawadmi in the Central province, were selected for analysis as these sites experience an annual average DNI of over $5.5 \mathrm{kWh} / \mathrm{m}^{2} /$ day.

The potential of all these locations for the installation of commercial central receiver plants was assessed accurately after optimizing the performance of the proposed 100 MWe central receiver solar thermal power plant. The TMY (typical meteorological year) data that include hourly DNI, ambient temperature, wind speed, and atmospheric pressure were decisive parameters for accurately predicting the solar field thermal power of a CSP plant. Table 1 shows the characteristics of the locations considered in this research work.

Table 1. Characteristics of the shortlisted locations analysed in this work.

\begin{tabular}{cccccc}
\hline Location & $\begin{array}{c}\text { Latitude and } \\
\text { Longitude }\end{array}$ & $\begin{array}{c}\text { Annual DNI } \\
\left(\mathbf{k W h} / \mathbf{m}^{2} / \mathbf{d a y}\right)\end{array}$ & $\begin{array}{c}\text { Average } \\
\text { Temperature }\left({ }^{\circ} \mathbf{C}\right)\end{array}$ & $\begin{array}{c}\text { Elevation } \\
(\mathbf{m})\end{array}$ & Data Source \\
\hline Yanbu (K.S.A) & $\begin{array}{c}24.1440 \mathrm{~N}, \\
38.0630 \mathrm{E}\end{array}$ & 6.86 & 28.7 & 7.9 & ISD \\
\hline Abha (K.S.A) & $\begin{array}{l}18.240 \mathrm{~N}, \\
42.6570 \mathrm{E}\end{array}$ & 6.52 & 19.0 & 2090.3 & ISD \\
\hline $\begin{array}{c}\text { Dawadmi } \\
\text { (K.S.A) }\end{array}$ & $\begin{array}{l}24.450 \mathrm{~N}, \\
44.1210 \mathrm{E}\end{array}$ & 6.11 & 22.3 & 922.3 & ISD \\
\hline
\end{tabular}

Figure 2 shows a comparison between the monthly variation of average DNI for a typical year at the three locations analysed in this study. From Figure 2, it is clear that the locations in Yanbu and Abha have a DNI greater than $5.5 \mathrm{kWh} / \mathrm{m}^{2} /$ day all year round, which is considered ideal for installing CSP plants. The location in Dawadmi is also found to offer a DNI level greater than $5.5 \mathrm{kWh} / \mathrm{m}^{2} /$ day except for the month of December. For Yanbu, a maximum DNI of $7.47 \mathrm{kWh} / \mathrm{m}^{2} /$ day is received for the month of June, while the minimum value of $6.23 \mathrm{kWh} / \mathrm{m}^{2} /$ day is recorded during the month of November. The location in Abha offers a peak value of $6.75 \mathrm{kWh} / \mathrm{m}^{2} /$ day during June, whereas the lowest DNI 
of $6.33 \mathrm{kWh} / \mathrm{m}^{2} /$ day is recorded during the month of February. Dawadmi records a maximum of $6.82 \mathrm{kWh} / \mathrm{m}^{2} /$ day in August and a low of $5.39 \mathrm{kWh} / \mathrm{m}^{2} /$ day during December.

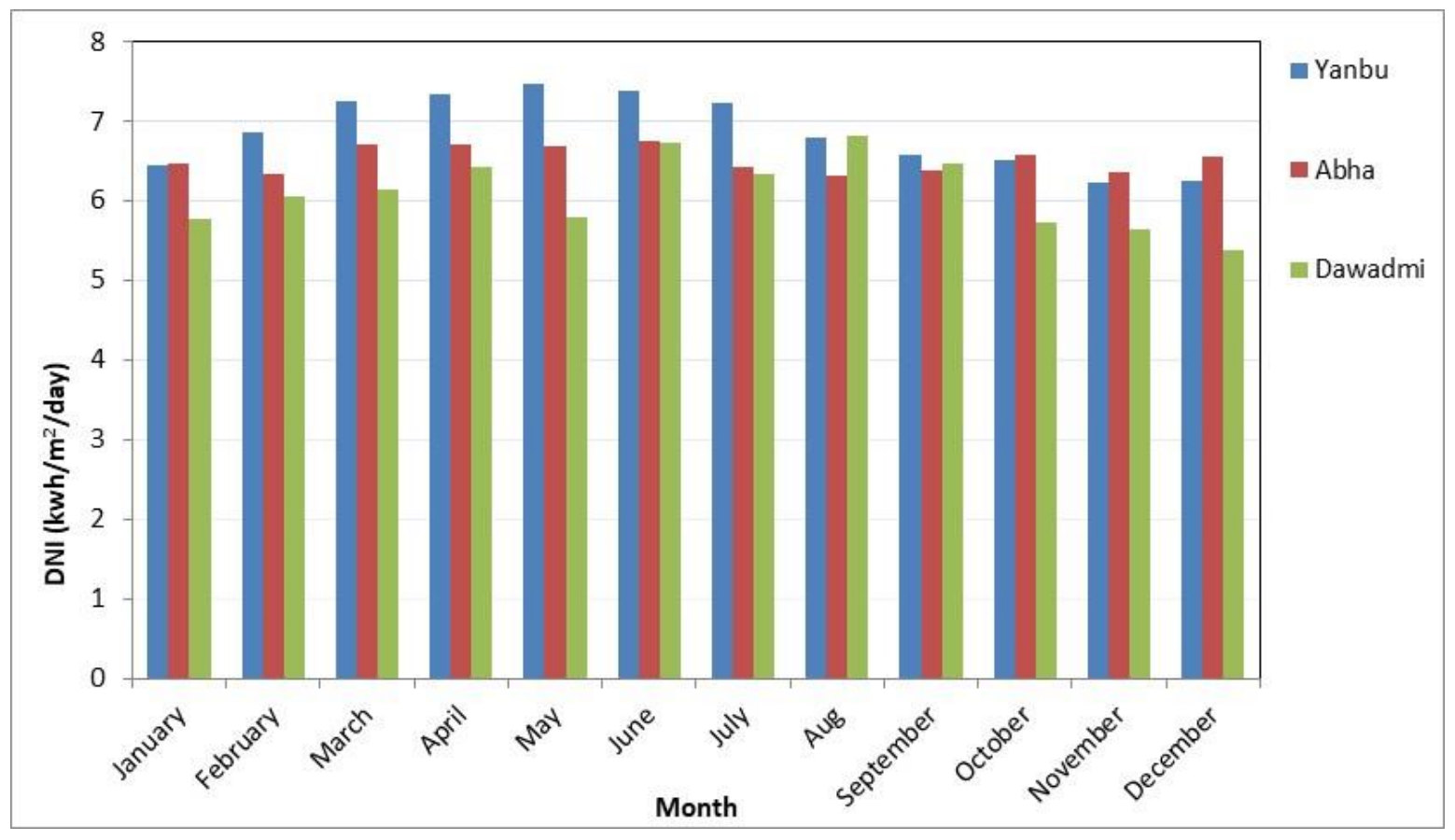

Figure 2. Average direct normal irradiance (DNI) for selected sites.

\section{Design of the 100MW Central Receiver Solar Thermal Power Plant}

The efficiency of a heliostat depends on its location with respect to the receiver. Unlike that of a parabolic trough collector system where the cosine effect depends only on the hour of the day, for a central receiver system, it depends on the location and the position of the sun as well.

The cosine angle can be determined in line with [17] and is given as

$$
\cos \left(\theta_{i, p}\right)=\sqrt{\frac{1+\cos \left(2 \theta_{i, p}\right)}{2}}
$$

The total annual solar energy $E_{\mathrm{s}}\left(\mathrm{Wh} / \mathrm{m}^{2}\right)$ per mirror area is

$$
E_{S}=\sum_{i=0}^{8760} D N I_{i} \times \cos \left(\theta_{i, p}\right)
$$

where $i$ refers to hour, and $p$ the location of the point.

Practically, heliostats are arranged in a typical fashion with gaps between them for shadowing and blocking considerations and maintenance requirements. Packing density (PD) is defined as the ratio of the mirror area to land area and is different for various locations in the heliostat field. Thus, for a central receiver system, the effect of PD also has to be considered to estimate the actual energy reflected.

Actual annual reflected energy per unit land area, at a point $p$ in the base field considering the effect of $\mathrm{PD}$, is given by

$$
E_{a}=(P D) \sum_{i=0}^{8760} D N I_{i} \times \cos \left(\theta_{i, p}\right)
$$


At design conditions, the thermal power of the heat transfer fluid (HTF) at which the plant generates the design electric power can be calculated as

$$
E_{t h_{h t f, d e s}}=\frac{P_{\text {des }} \times 10^{6}}{\eta_{E_{P B}} \times \eta_{H E}}
$$

Therefore, the thermal power that needs to be collected from the heliostat field can be calculated by the following equation

$$
E_{t h_{\text {des }}}=\frac{E_{t h_{h t, d e s}}}{\eta_{\text {receiver }}}
$$

Substituting (4) in (5),

$$
E_{\text {th }}=\frac{P_{\text {des }} \times 10^{6}}{\eta_{\text {receiver }} \times \eta_{H E} \times \eta_{E_{P B}}}
$$

One of the main characteristics of CSP plants is their ability to store thermal energy. Hence, these systems are capable of supplying firm power to the grid when solar radiation is weak and can generate power even after sunset, depending on their thermal energy storage (TES) capacity.

The maximum energy that can be stored can be determined by the following equation:

$$
E_{T E S_{\max }}=\frac{E_{t h_{h t f, d e s}} \times H_{t e s}}{\eta_{S_{H E}}}
$$

The two main parameters that are used to assess the overall performance of the central receiver plant design is the capacity factor (CF) and solar-to-electric conversion efficiency. A utility level CSP plant design is said to be commercially viable only if both $\mathrm{CF}$ and solar-to-electric conversion efficiency of the plant is optimized with regard to appropriate TES capacity for the location.

Capacity factor is defined as the ratio of actual output generated from the plant in a year to the maximum possible output from the plant during the period under ideal conditions and is given by the following expression:

$$
C F=\frac{\text { Gross Annual Electricity Generated }}{P_{\text {des }} \times 10^{6} \times 8760}
$$

The annual solar-to-electric conversion efficiency $\left(\eta_{s e}\right)$ is the ratio of the total annual electricity generated from the plant to the total incident solar energy received by heliostats.

$$
\eta_{s e}=\frac{\text { Total Annual Electricity Generated }}{\text { Total incident solar energy received by the heliostats }}
$$

\section{Characteristics of the Proposed CSP Plant Design}

Table 2 shows the design parameters of the proposed $100 \mathrm{MW}$ central receiver solar thermal power plant. The various design parameters related to the heliostats, receiver, and the tower are listed in the table. For utility scale power generation, it is very important to operate the plant with optimum efficiency, TES capacity, capacity factor, and least levelized cost of energy (LCOE). Thus, for a central receiver solar thermal power plant, the main design parameters, such as solar multiple (SM) and number of hours of thermal energy storage, can only be arrived at after conducting detailed performance analysis of the proposed design. 
Table 2. Design parameters of the central receiver plant.

\begin{tabular}{cc}
\hline Parameter & Value \\
\hline Name Plate Capacity & $100 \mathrm{MW}$ \\
Design Point DNI & $950 \mathrm{~W} / \mathrm{m}^{2}$ \\
Heliostat width & $12.2 \mathrm{~m}$ \\
Heliostat height & $12.2 \mathrm{~m}$ \\
Receiver type & Cylindrical \\
Receiver Diameter & $17.61 \mathrm{~m}$ \\
Receiver Height & $20.41 \mathrm{~m}$ \\
HTF Type & Hitec molten salt \\
Storage Type & Two Tank \\
Tower Height & $203 \mathrm{~m}$ \\
\hline
\end{tabular}

SolarPILOT software (NREL, Colorado, USA) is used to model the heliostat field layout corresponding to each value of SM in each of the locations. One of the main highlights of the software is that it can be integrated with the System Advisor Model (SAM) from NREL and can optimize the field layout for better performance. The software uses the analytical flux image Hermite series approximation to individual heliostat images rather than large groups or zones of heliostats and hence can characterize a wide variety of heliostat field layouts [18]. Table 3 lists the number of heliostats for each value of SM in all the three locations. From the table, it is clear that as the SM value is increased, the number of heliostats in the solar field layout also increases. As an example, Figure 3 shows the heliostat field layout of Yanbu corresponding to an SM of 2.4 comprising 8456 heliostats. The following section details the optimization procedure adopted in this research work so as to determine the optimal design parameters of the plant in each of the three locations. Furthermore, the performance analysis of this optimal configuration was carried out to determine the efficiency, capacity factor, and LCOE of the proposed plant configuration.

Table 3. Number of heliostats corresponding to solar multiple (SM) in each locations.

\begin{tabular}{cccc}
\hline \multirow{2}{*}{ Solar Multiple } & \multicolumn{3}{c}{ Number of Heliostats } \\
\cline { 2 - 4 } & Yanbu & Abha & Dawadmi \\
\hline 1 & 3444 & 3465 & 3432 \\
1.2 & 4098 & 4119 & 4084 \\
1.4 & 4770 & 4785 & 4754 \\
1.6 & 5465 & 5463 & 5446 \\
1.8 & 6166 & 6175 & 6146 \\
2 & 6903 & 6897 & 6881 \\
2.2 & 7656 & 7658 & 7632 \\
2.4 & 8456 & 8459 & 8429 \\
2.6 & 9305 & 9293 & 9273 \\
\hline
\end{tabular}




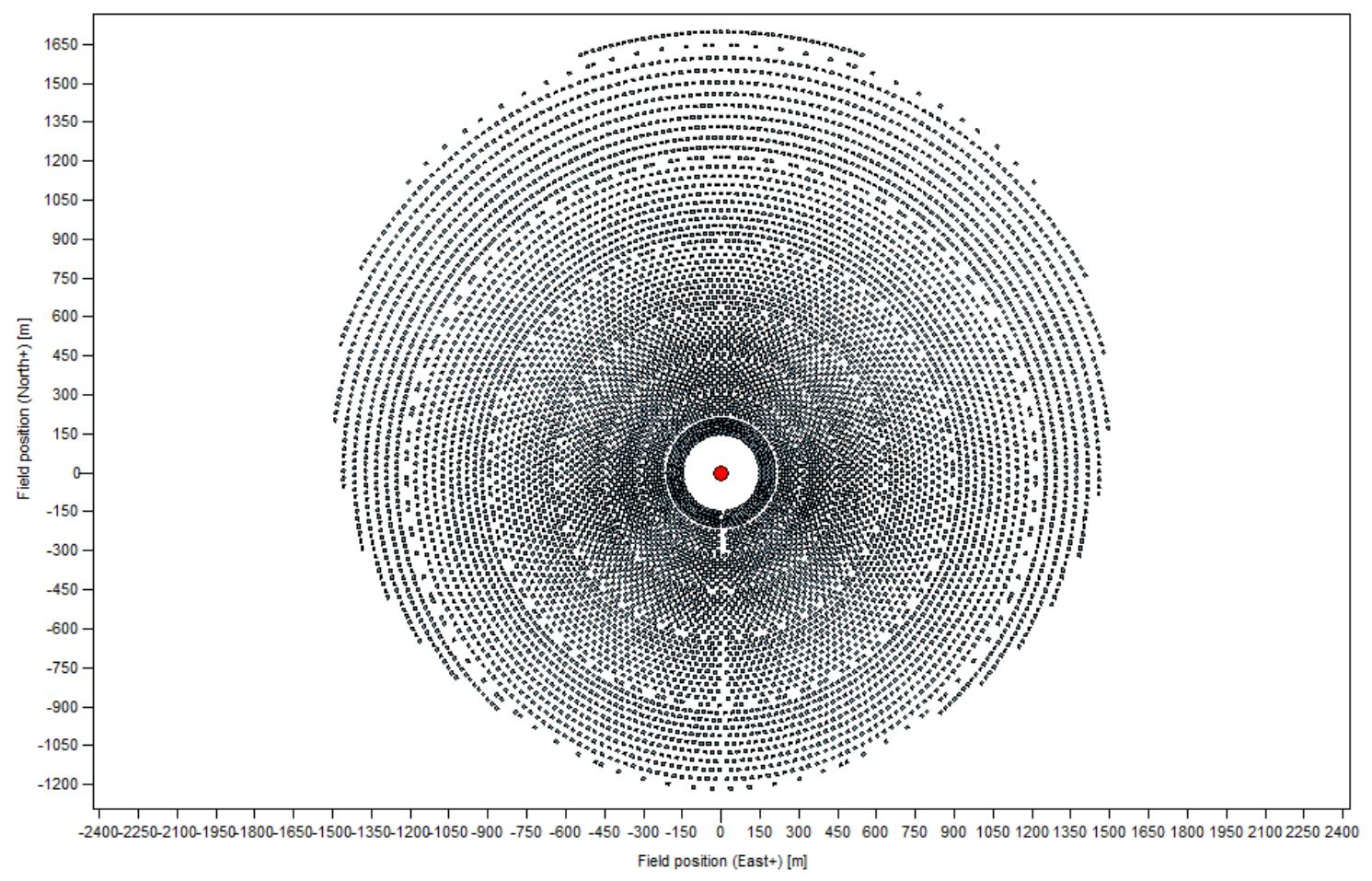

Figure 3. Heliostat field layout for Yanbu generated from SolarPILOT.

\section{Results and Discussion}

Because the DNI characteristics vary distinctly with respect to each location, it is not prudent to fix the SM corresponding to each location and thereafter optimize the TES capacity to that particular value of SM. This kind of optimization approach will result in reduced plant efficiency with high LCOE.

The optimization approach presented in this work aims to arrive at the best possible design parameters suiting a particular location in accordance with its DNI profile. First, the variation of LCOE with SM was analysed for different TES capacities in all the locations investigated in the study. This analysis was followed by estimating the efficiency of the plant with SM for different TES capacities. Based on these two analyses, an optimal value of SM was fixed, and subsequently, the optimal TES capacity of the plant could be obtained based on the peak efficiency value.

Figures 4-6 show the variation of LCOE with SM pertaining to different TES capacities in Yanbu, Abha, and Dawadmi, respectively. From the figures, it is clear that once the SM value increased, the LCOE of the plant started to come down, depending on the TES capacity of the plant. This fact is obvious as increasing the SM increases the number of heliostats tapping the solar energy, thereby generating more power and subsequently bringing down the LCOE. However, if the plant does not have TES capacity or has less TES capacity, there is no point in increasing the SM beyond a point when LCOE starts to increase due to underutilization of the solar field, which would result in capital losses and uneconomic operation of the plant. Figures 4-6 also depict the fact that it is not possible to fix the SM solely based on variation of LCOE as other plant performance parameters, such as capacity factor and plant efficiency, also have to be accounted for to reach the optimal design parameters. However, this analysis gives an initial idea regarding the range of SM values that can be investigated further for optimization purposes. The SM range that can be considered for investigation in the locations of Yanbu and Abha as per Figures 4 and 5 falls between 2.2 and 2.6, whereas that for Dawadmi is between 2 and 2.6. 


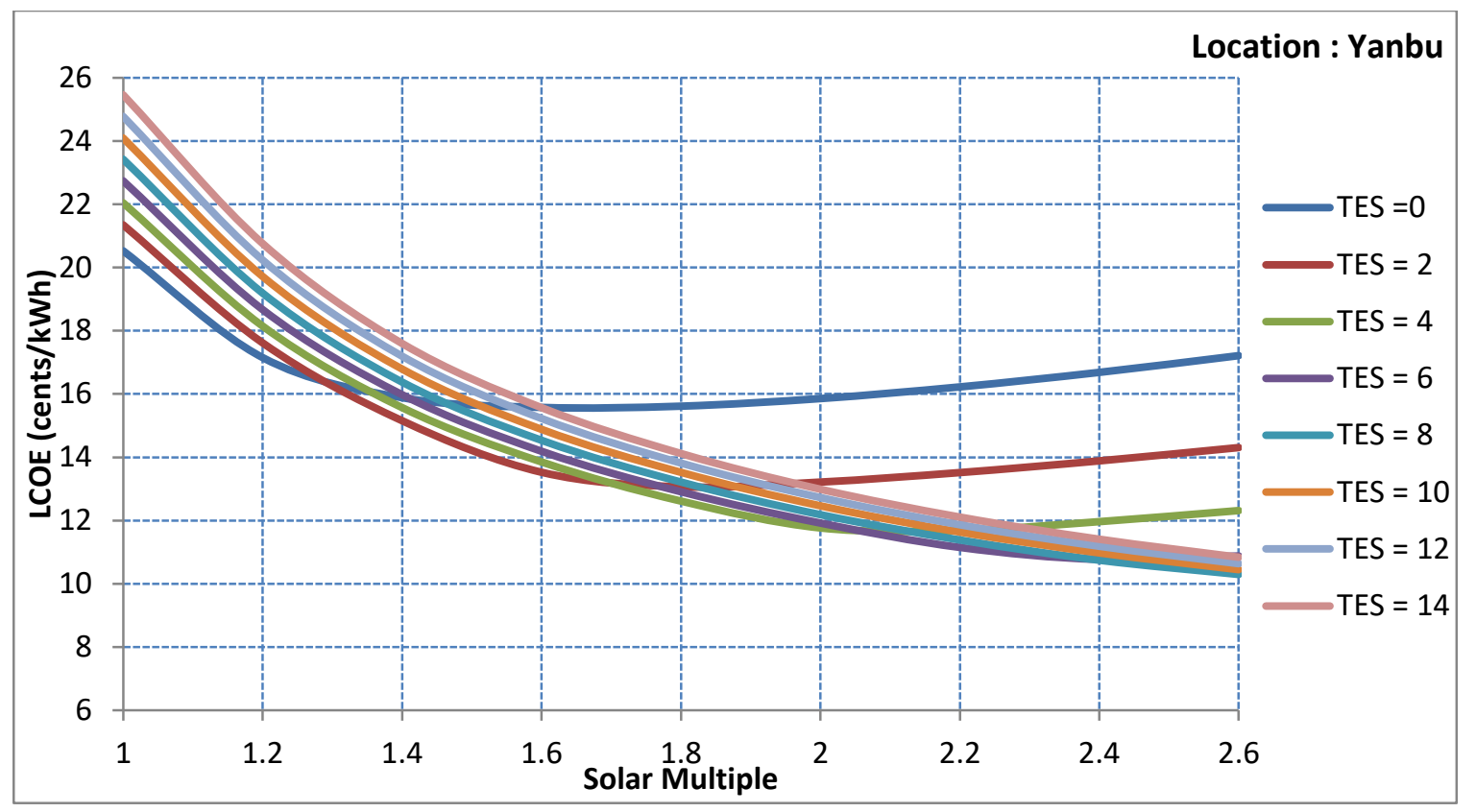

Figure 4. Variation of solar multiple and levelized cost of energy (LCOE) with thermal energy storage (TES) for the location in Yanbu.

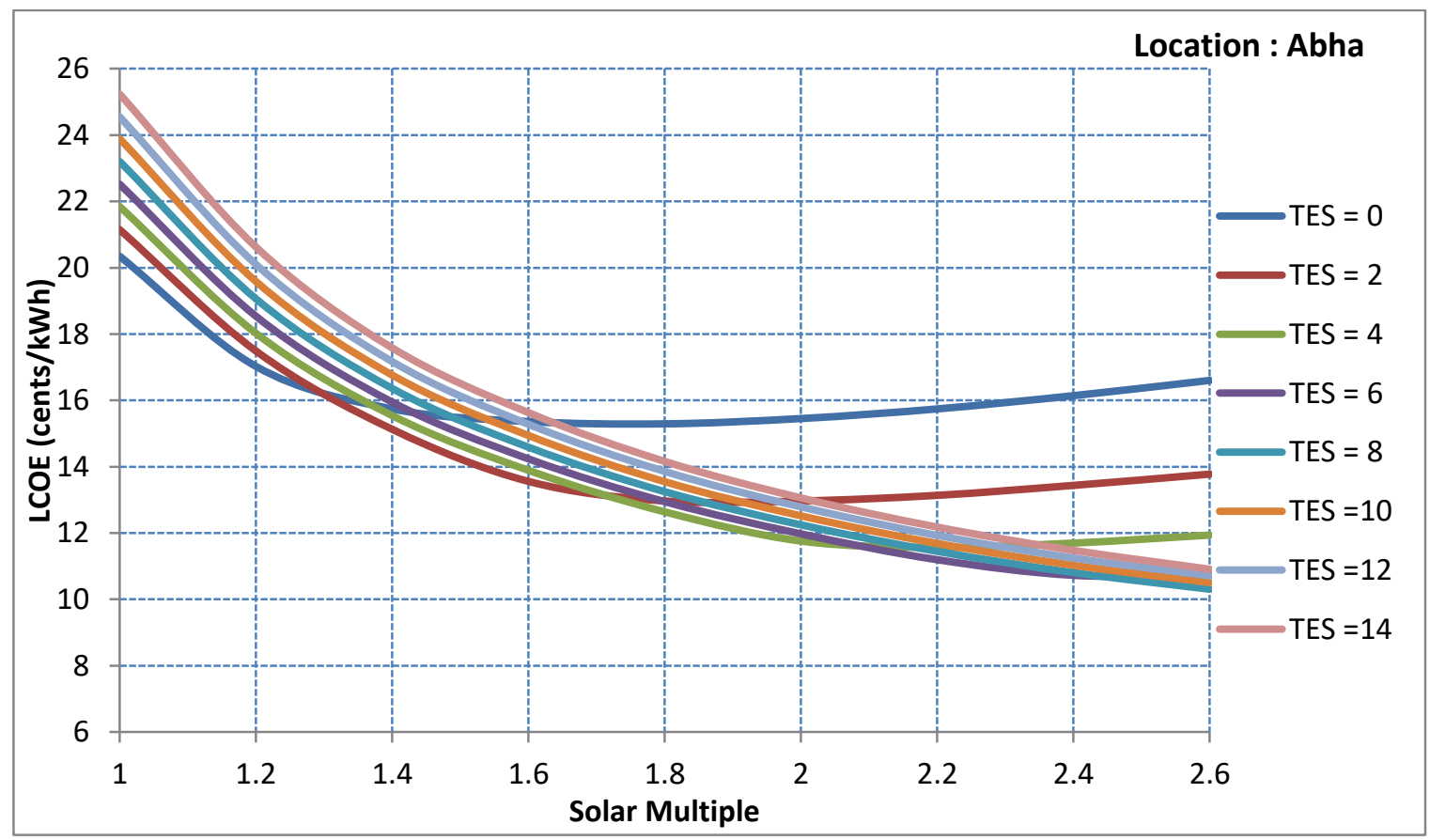

Figure 5. Variation of solar multiple and LCOE with TES for the location in Abha. 


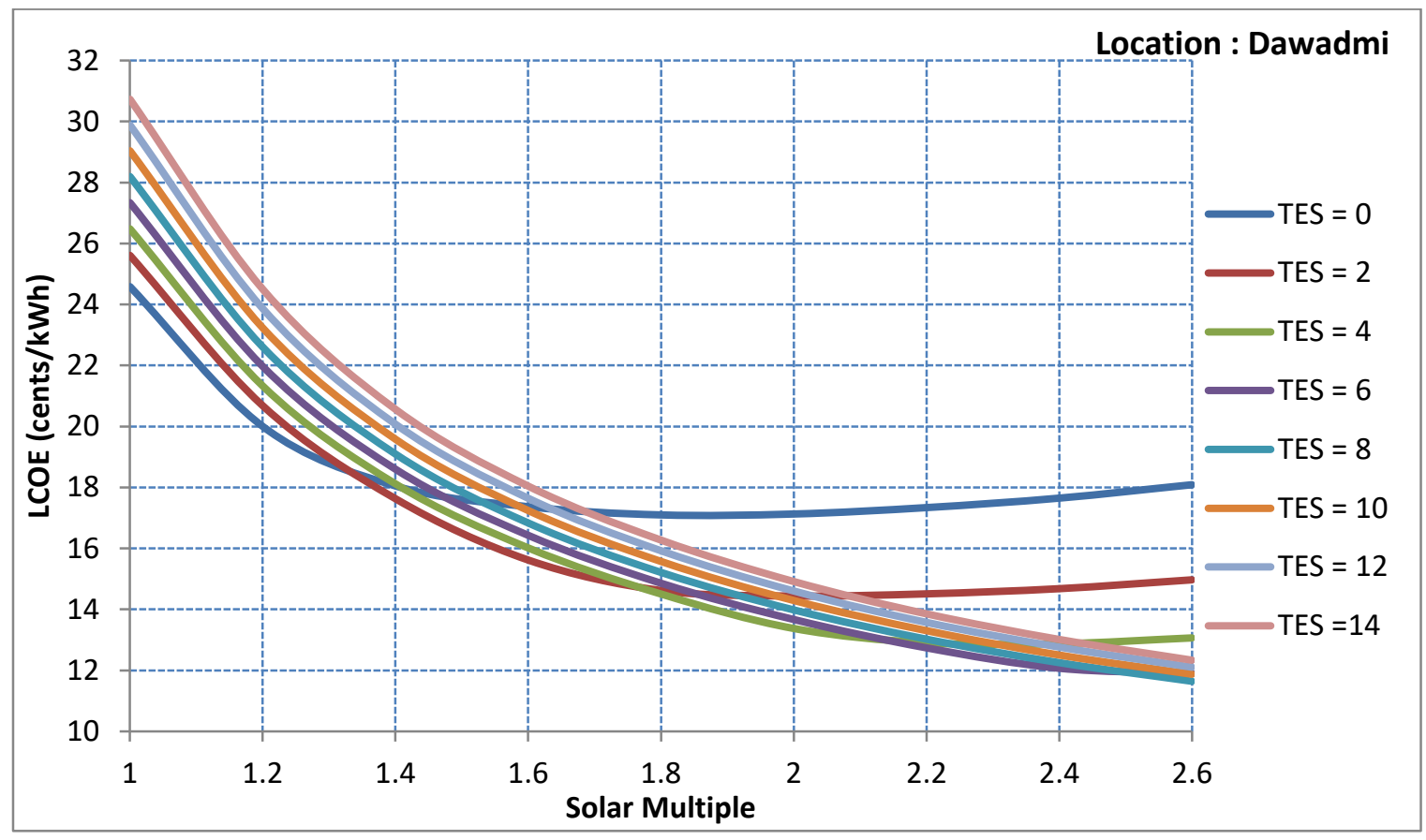

Figure 6. Variation of solar multiple and LCOE with TES for the location in Dawadmi.

Figures 7-9 show the variation of efficiency with SM for different TES capacities in Yanbu, Abha, and Dawadmi, respectively. From the figures, it is clear that the efficiency value peaks for a particular value of SM for each TES value, and thereafter, it decreases. But other parameters such as LCOE and $\mathrm{CF}$ also have to be considered simultaneously to decide the optimal SM value. Thus, based on the tradeoff between the two performance parameters such as efficiency and CF of the plant, as well as the economical parameter LCOE, it was found that the ideal value of SM for all the three locations is 2.4.

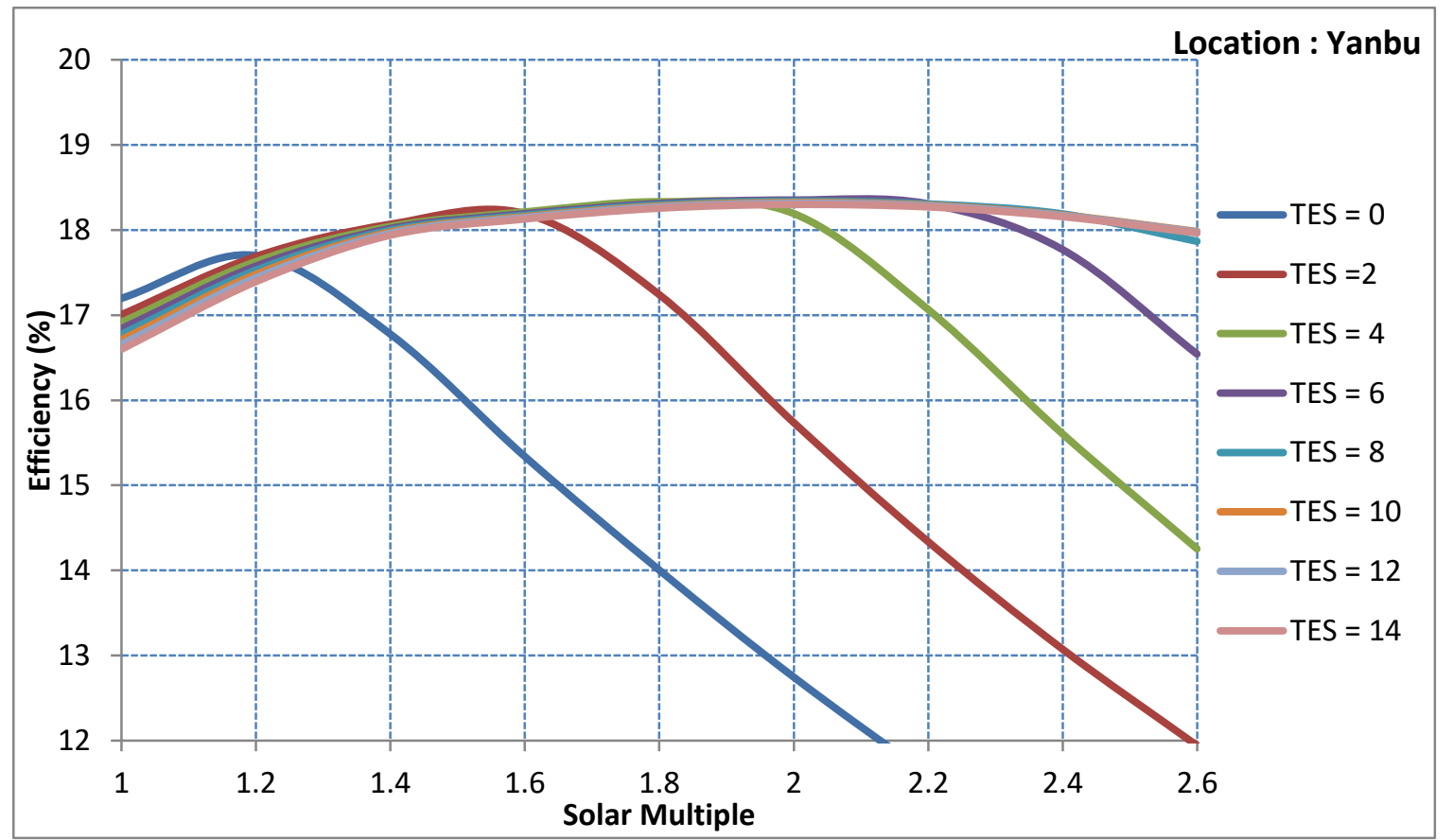

Figure 7. Variation of plant efficiency with solar multiple with full load hours of TES for the location in Yanbu. 


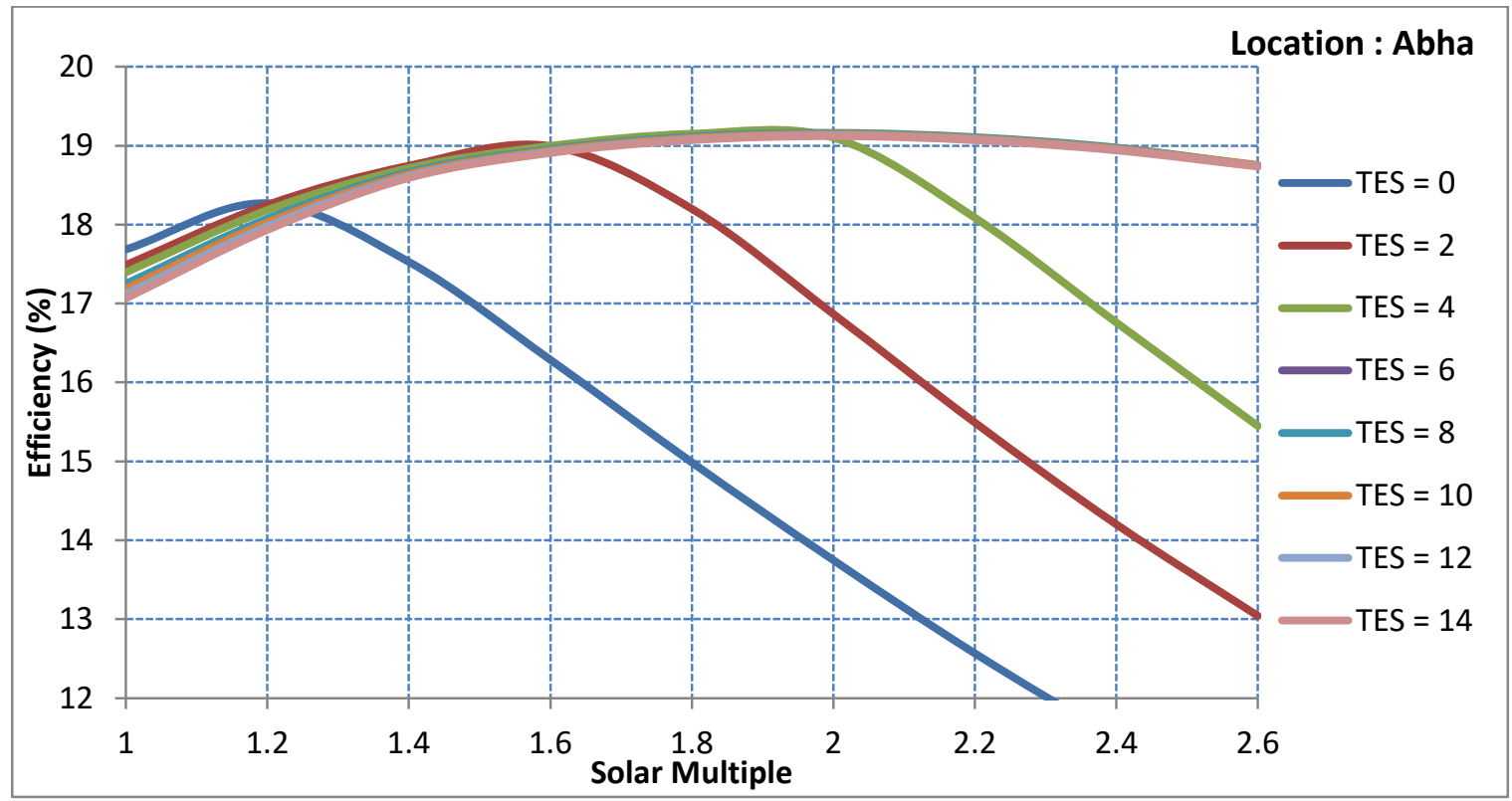

Figure 8. Variation of plant efficiency with solar multiple with full load hours of TES for the location in Abha.

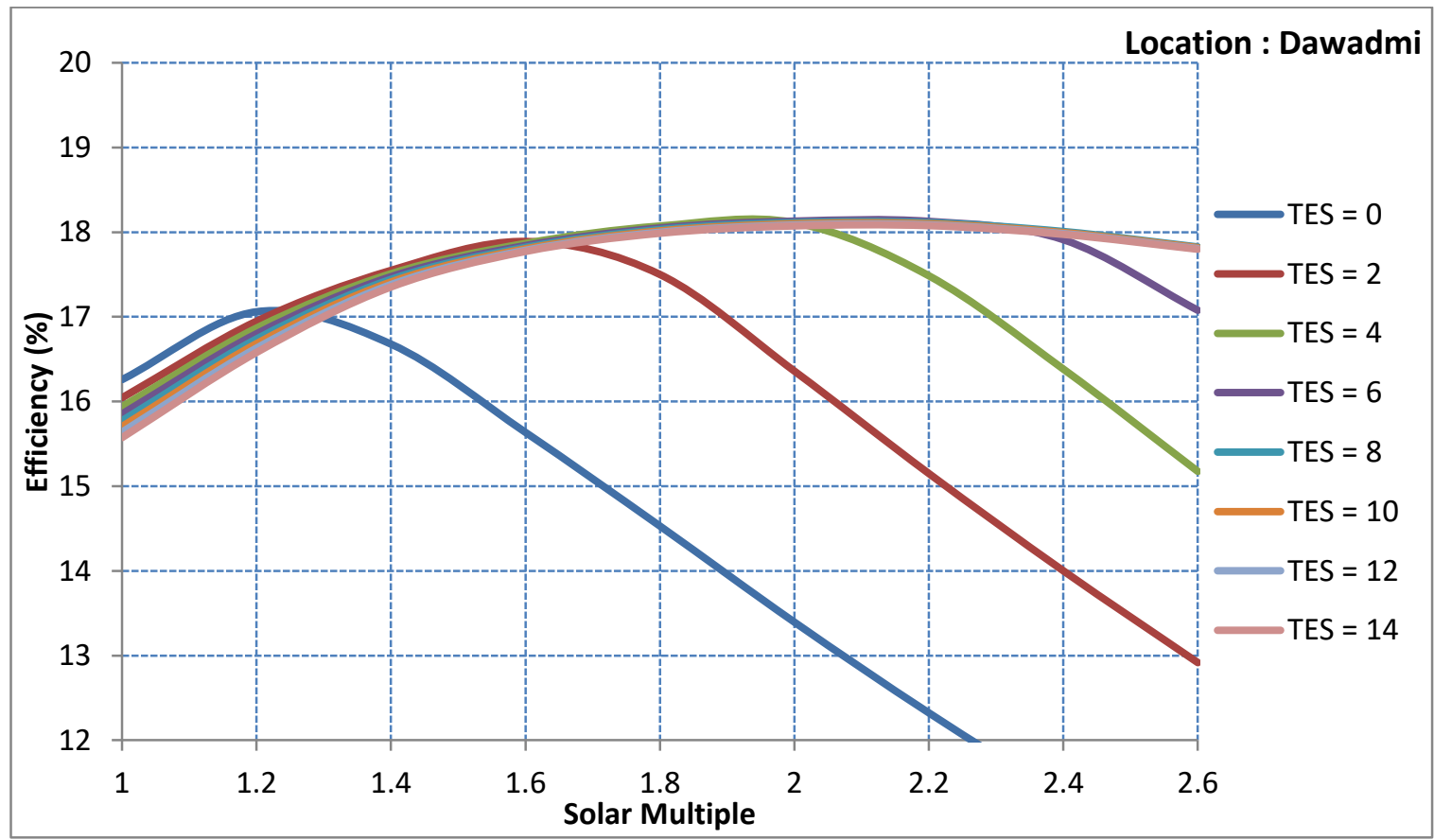

Figure 9. Variation of plant efficiency with solar multiple with full load hours of TES for the location in Dawadmi.

The next step of the optimization procedure is to find the optimal number of hours of TES corresponding to an SM of 2.4 in each of the locations. Figures 10-12 depict the variation of plant efficiency and LCOE for different TES values at $\mathrm{SM}=2.4$ at Yanbu, Abha, and Dawadmi, respectively. From the figures, it is clear that the efficiency of the proposed plant in all the locations peaks when $8 \mathrm{~h}$ of thermal energy storage is adopted. For Yanbu, plant efficiency of $18.19 \%$ can be achieved with an LCOE of 10.75 cents $/ \mathrm{kWh}$. The highest value of plant efficiency can be obtained from the location in Abha, which can offer an efficiency of $18.97 \%$ with an LCOE of 10.81 cents $/ \mathrm{kWh}$. The location in 
Dawadmi, which has relatively weak DNI characteristics when compared to the other two locations, has a higher LCOE value of 12.25 cents/kWh and the lowest plant efficiency of $18.01 \%$.

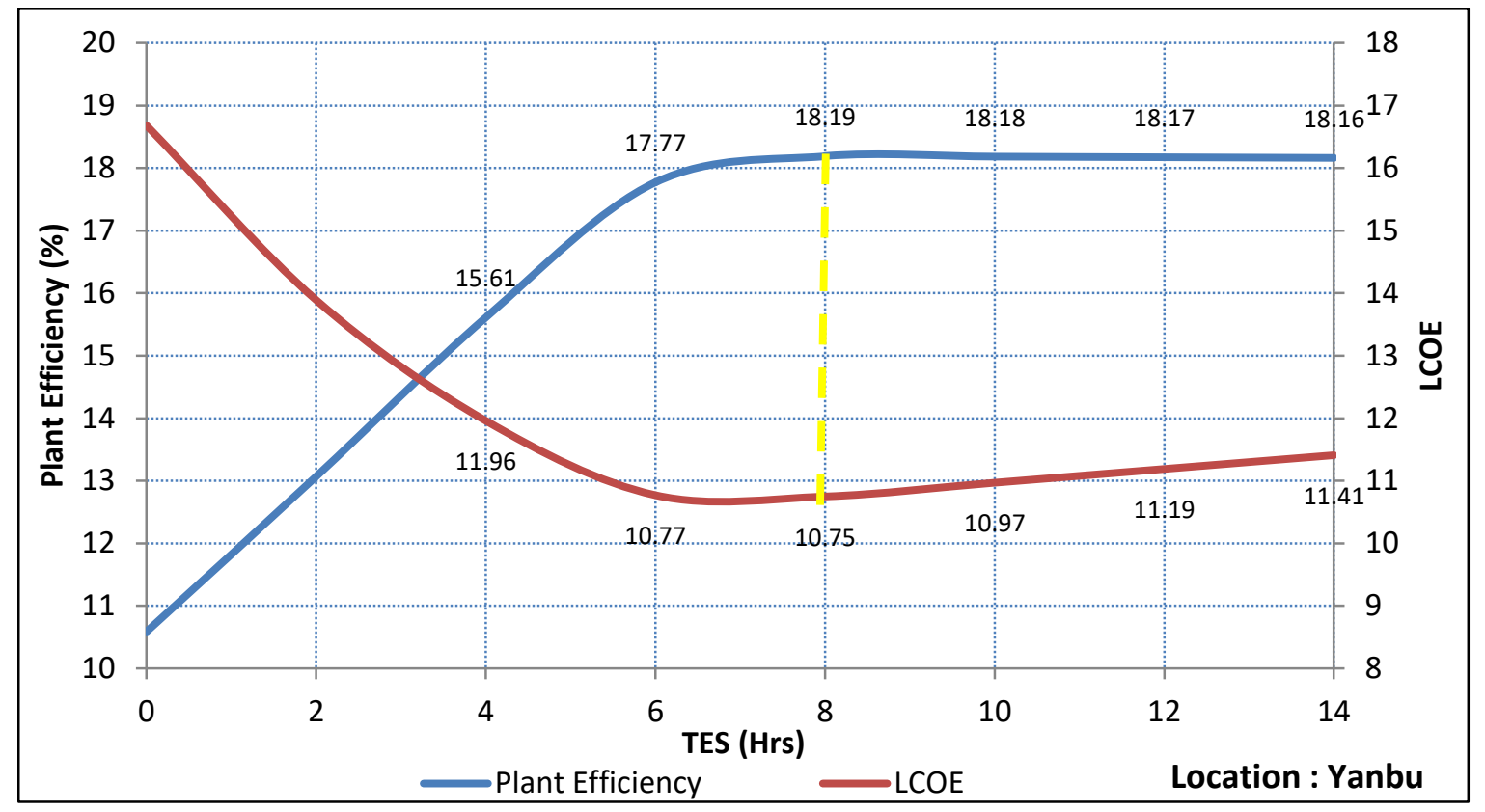

Figure 10. Plant efficiency and LCOE variation with full load hours of TES at SM = 2.4 in Yanbu.

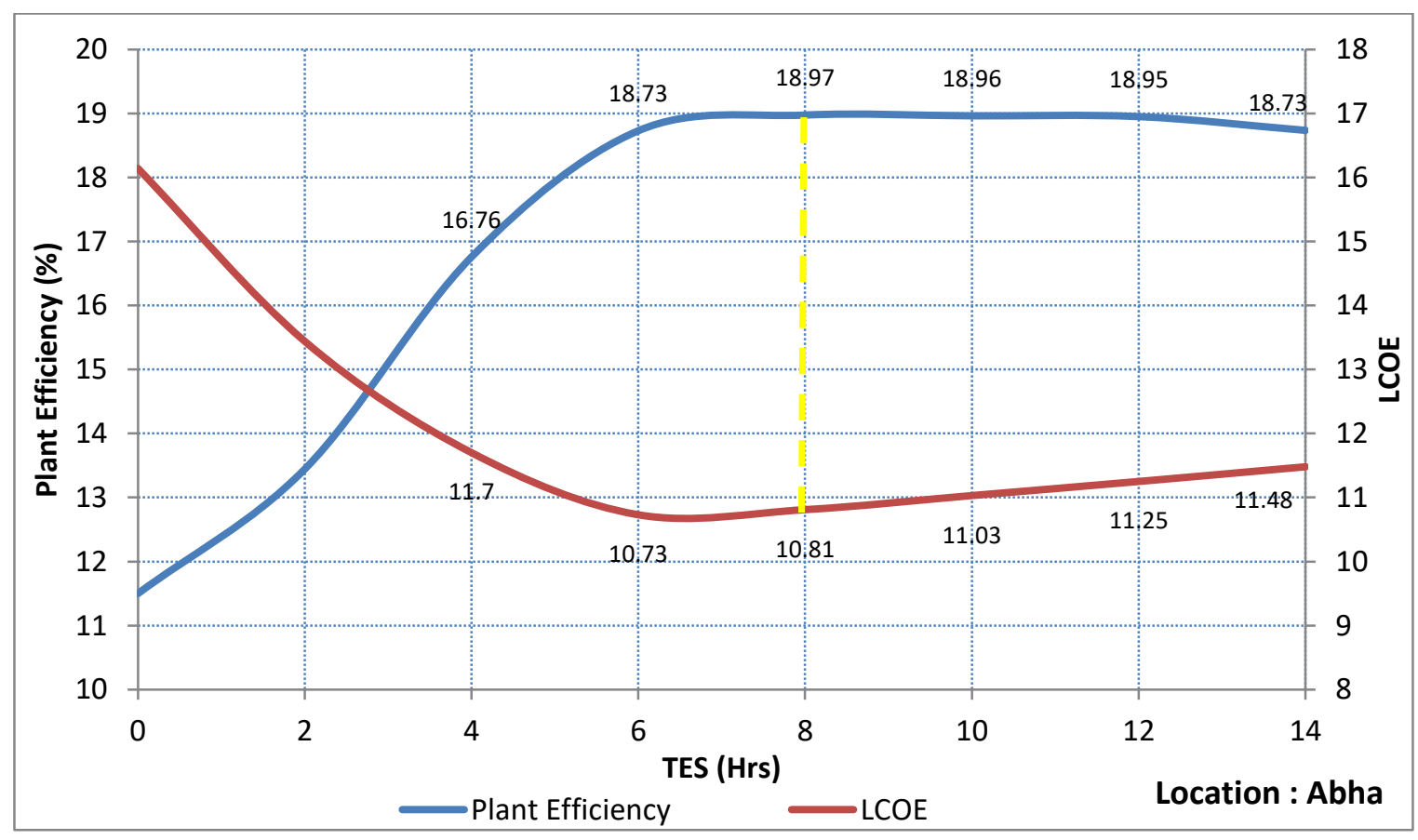

Figure 11. Plant efficiency and LCOE variation with full load hours of TES at SM $=2.4$ in Abha. 


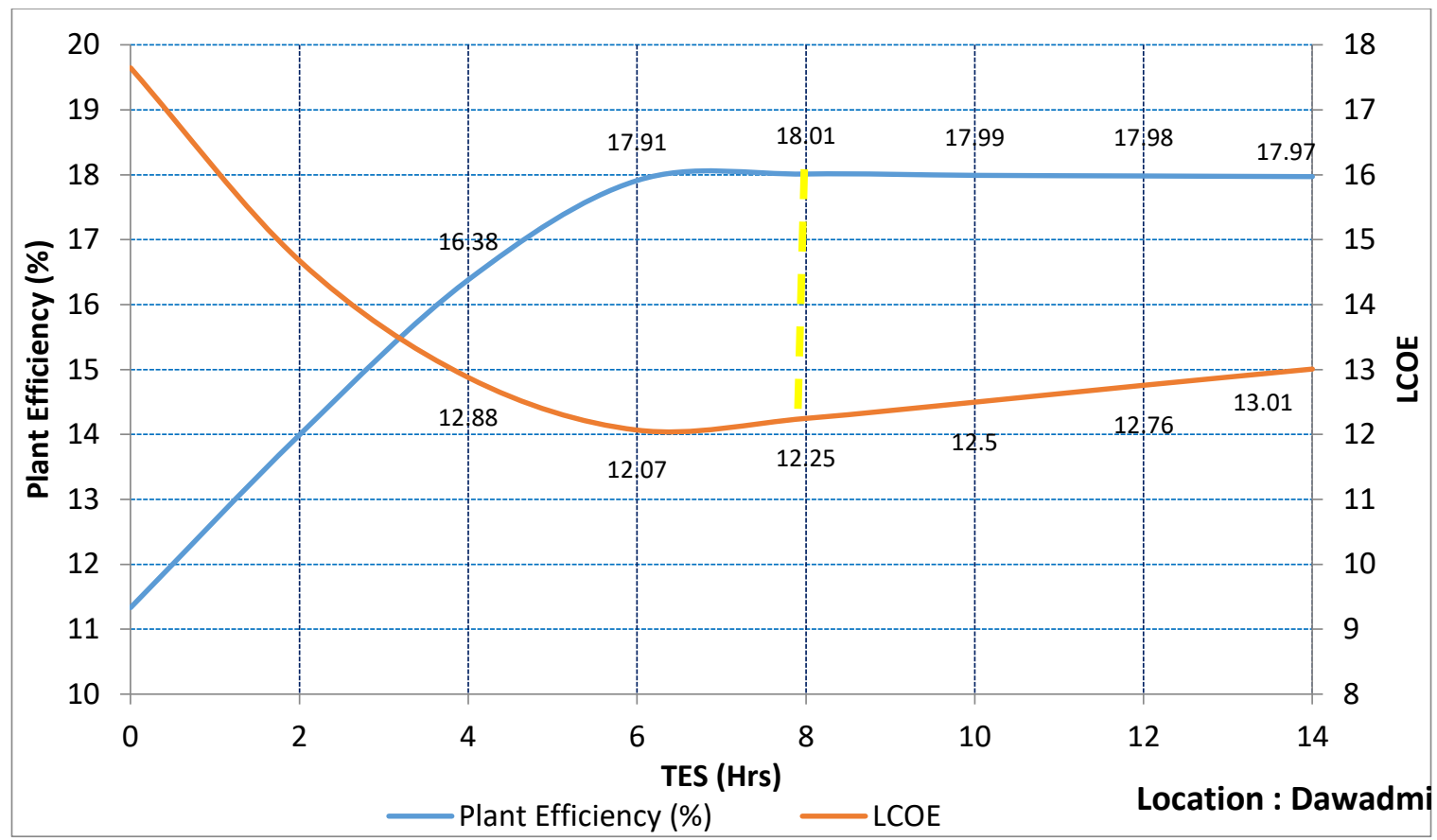

Figure 12. Plant efficiency and LCOE variation with full load hours of TES at SM = 2.4 in Dawadmi.

Figure 13 shows the performance comparison of the optimized central receiver solar thermal plant configuration in each of the three locations. From the figure, it is evident that Yanbu and Abha are most suitable for the installation of central receiver CSP plants as they can offer CF of 61.1 and 60.7, respectively, with superior plant efficiency and low LCOE. This high value of CF obtained as a result of the optimization approach adopted in the study is a good indicator that a plant can be operated at its optimum output power level. Table 4 summarizes the results obtained for the final optimized plant configuration in all the three locations investigated in this research work. From the table, it is clear that plant efficiencies of $18 \%$ and above can be achieved in all the three locations. The LCOE, which depends on the amount of annual energy that can be generated from the plant, is the least in Yanbu, 10.75 cents/kWh, while the total amount of energy generated from the location is the highest, $539.61 \mathrm{GWh}$. The CF of the proposed plant in Yanbu is also the highest with a value of 61.1\%. The location in Abha, which can generate $536.31 \mathrm{GWh}$ annually, offers an LCOE and CF of 10.81 cents $/ \mathrm{kWh}$ and $60.7 \%$, respectively. The annual energy generated from Dawadmi is the least, $470.5 \mathrm{GWh}$, which can be attributed to the weak DNI profile of the region, and the LCOE and CF values are respectively 12.25 cents/kWh and $53.3 \%$.

Table 4. Annual energy yield and comparison of performance parameters for the optimized concentrated solar power (CSP) plant configuration for the three locations.

\begin{tabular}{cccc}
\hline Parameter & Yanbu & Abha & Dawadmi \\
\hline Annual Energy Generated (GWh) & 539.61 & 536.31 & 470.5 \\
Solar Multiple & 2.4 & 2.4 & 2.4 \\
Full load hours of TES & 8 & 8 & 8 \\
Capacity Factor (\%) & 61.1 & 60.7 & 53.3 \\
LCOE (cents/kWh) & 10.75 & 10.81 & 12.25 \\
Plant Efficiency (\%) & 18.19 & 18.97 & 18 \\
\hline
\end{tabular}




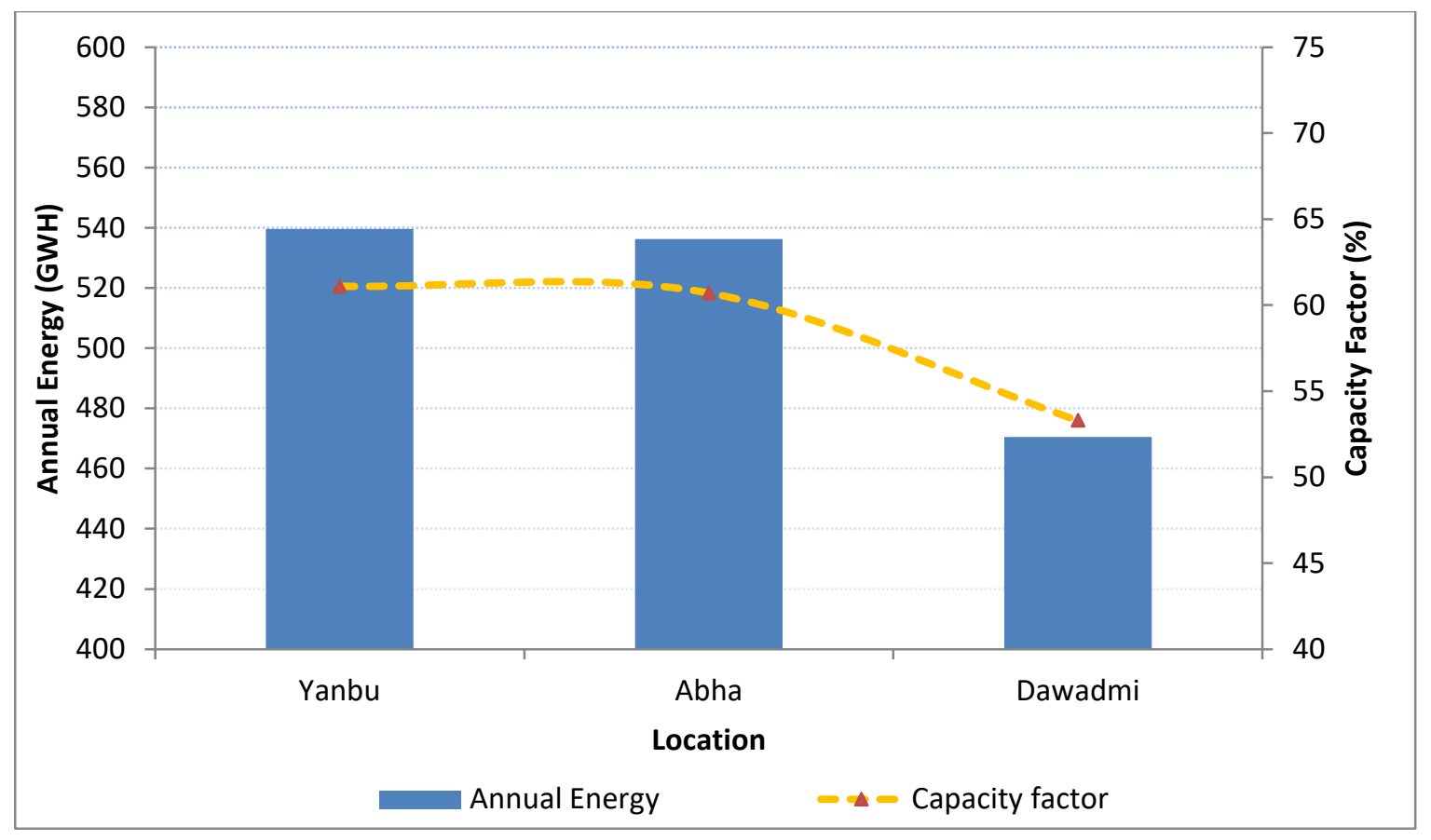

Figure 13. Performance comparison of optimized plant configurations in three locations.

Presently, there are only two central receiver solar thermal power plants that have a capacity of more than 100 MWe operational in the world. The Ivanpah Solar Tower plant in California, United States, with a capacity of $377 \mathrm{MW}$ is the largest and has no thermal energy storage capability. The design parameters of the 110 MWe Crescent Dunes Central Receiver plant in Nevada, United States, which has $10 \mathrm{~h}$ of TES capacity, is used for comparing the performance parameters of the proposed design arrived in this paper. Table 5 shows the performance comparison of the proposed plant design with the performance parameters of the Crescent Dunes Central Receiver plant.

Table 5. Performance comparison of the proposed design with parameters of Crescent Dunes Central Receiver plant.

\begin{tabular}{ccccc}
\hline Parameter & Crescent Dunes [19,20] & Yanbu & Abha & Dawadmi \\
\hline Plant Capacity & $110 \mathrm{MWe}$ & $100 \mathrm{MWe}$ & $100 \mathrm{MWe}$ & $100 \mathrm{MWe}$ \\
TES capacity (Hours) & 10 & 8 & 8 & 8 \\
Expected Annual Energy & 500 & 539.61 & 536.31 & 470.5 \\
Generated (GWh) & 51.89 & 61.1 & 60.7 & 53.3 \\
Capacity Factor (\%) & 16.86 & 18.19 & 18.97 & 18 \\
Plant Efficiency (\%) & &
\end{tabular}

From Table 5, it is clear that both the plant efficiency and capacity factor of the proposed utility level central receiver plant design in all the three shortlisted sites are superior than those in the Crescent Dunes plant. Similar is the case for the expected annual energy that can be generated from the two locations in Yanbu and Abha. Thus, the optimization approach presented in this work can be effectively used to reach the best possible design configuration of the central receiver solar thermal plant suiting a potential site.

\section{Conclusions}

The design, performance analysis, and optimization of a 100 MWe central receiver solar thermal power plant with thermal energy storage meant for utility scale applications were carried out for three locations in Saudi Arabia. The results show that by properly optimizing the design of central 
receiver plants, it is possible to obtain a plant configuration that can offer superior plant efficiency and a capacity factor with the lowest value of LCOE. From the analysis of the optimized design, an annual energy of 559.61 GWh can be generated in Yanbu with eight hours of thermal energy storage, plant efficiency of $18.19 \%$, and a capacity factor of $61.1 \%$. The central receiver plant in Abha can offer an annual energy of $536.31 \mathrm{GWh}$ with the highest plant efficiency of $18.97 \%$ and a capacity factor of $60.7 \%$. The performance of the proposed design in the two locations of Yanbu and Abha fares better when compared to the operational plant data of the central receiver plant in Crescent Dunes. Based on the findings of the study, the proposed 100 MWe central receiver solar thermal power plants with thermal energy storage were found to be ideally suited for specific locations in Saudi Arabia.

Funding: This research was funded by [Deanship of Scientific Research, Majmaah University] grant number [38/119].

Acknowledgments: The authors would like to thank the Deanship of Scientific Research, Majmaah University (Contract No. 38/119), Majmaah, 11952, Saudi Arabia for supporting this research project.

Conflicts of Interest: The author declares no conflict of interest.

\section{Nomenclature}

$\begin{array}{ll}\theta_{i, p} & \text { Angle of incidence at point } \mathrm{p} \text { for } \mathrm{i}^{\text {th }} \text { hour (degree) } \\ E_{S} & \text { Total Annual Solar Energy }\left(\mathrm{Wh} / \mathrm{m}^{2}\right) \\ P D & \text { Packing Density at point } \mathrm{p} \text { of heliostat field } \\ P_{\text {des }} & \text { Design Electrical Capacity of the plant (MW) } \\ \eta_{E_{P B}} & \text { Power Block Efficiency } \\ \eta_{\text {receiver }} & \text { Receiver Efficiency } \\ E_{T E S_{m a x}} & \text { Maximum thermal energy storage capacity }(\mathrm{Wh}) \\ D N I_{i} & \text { Direct normal irradiance at the location for } \mathrm{i}^{\text {th }} \text { hour } \\ & \left(\mathrm{W} / \mathrm{m}^{2}\right) \\ E_{a} & \text { Actual Annual reflected Energy per unit land area } \\ & \left(\mathrm{Wh} / \mathrm{m}^{2}\right) \\ E_{t h_{h t f, d e s}} & \text { Thermal power of HTF required for design electric } \\ & \text { power (W) } \\ E_{t h_{\text {des }}} & \text { Design point thermal power to be collected from field } \\ \eta_{H E} & \text { (W) } \\ \eta_{S_{H E}} & \text { Heat exchanger efficiency } \\ H_{t e s} & \text { Storage heat exchanger efficiency }\end{array}$

\section{Abbreviations}

$\begin{array}{ll}\text { PTC } & \text { Parabolic Trough Collector } \\ \text { HTF } & \text { Heat Transfer Fluid } \\ \text { CSP } & \text { Concentrated solar power } \\ \text { ISD } & \text { Integrated Surface Database } \\ \text { DNI } & \text { Direct normal irradiance } \\ \text { SAM } & \text { Solar Advisor model } \\ \text { CF } & \text { Capacity Factor }\end{array}$

\section{References}

1. International Energy Agency (IEA). Technology Roadmap: Wind Energy; OECD publishing: Paris, France, 2013; Available online: https://www.iea.org (accessed on 14 March 2018).

2. International Renewable Energy Agency (IRENA). Renewable Capacity Statistics; IRENA: Abu Dhabi, UAE, 2019; Available online: https://www.irena.org (accessed on 22 July 2018).

3. Zell, E.; Gasim, S.; Wilcox, S.; Katamoura, S.; Stoffel, T.; Shibli, H.; Engel-Cox, J.; Al Subie, M. Assessment of solar radiation resources in Saudi Arabia. Sol. Energy 2015, 119, 422-438. [CrossRef] 
4. Ho, C.K. Advances in Central Receivers for concentrating solar applications. Sol. Energy 2017, 152, 38-56. [CrossRef]

5. Ramli, M.A.M.; Twaha, S.; Al-hamouz, Z. Analyzing the potential and progress of distributed generation applications in Saudi Arabia: The case of solar and wind resources. Renew. Sustain. Energy Rev. 2017, 70, 287-297. [CrossRef]

6. Jafrancesco, D.; Cardoso, J.P.; Mutuberria, A.; Leonardi, E.; Les, I.; Sansoni, P.; Francini, F.; Fontani, D. Optical simulation of a Central Receiver system: Comparison of different software tools. Renew. Sustain. Energy Rev. 2018, 94, 792-803. [CrossRef]

7. Avila-marin, A.L.; Fernandez-reche, J.; Tellez, F.M. Evaluation of the potential of Central Receiver solar power plants: Configuration, optimization and trends. Appl. Energy 2013, 112, 274-288. [CrossRef]

8. Eddhibi, F.; Amara, M.B.; Balghouthi, M. Design and analysis of a heliostat field layout with reduced shading effect in southern Tunisia. Int. J. Hydrogen Energy 2017, 42, 28973-28996. [CrossRef]

9. Benammar, S.; Khellaf, A.; Mohammedi, K. Contribution to the modeling and simulation of solar Power Tower plants using energy analysis. Energy Convers. Manag. 2014, 78, 923-930. [CrossRef]

10. Carrizosa, E.; Domínguez-bravo, C.; Fernández-cara, E.; Quero, M. A heuristic method for simultaneous Tower and pattern-free fi eld optimization on solar power systems. Comput. Oper. Res. 2015, 57, 109-122. [CrossRef]

11. Yu, Q.; Wang, Z.; Xu, E.; Li, X.; Guo, M. Modeling and dynamic simulation of the collector and Receiver system of 1 MWe DAHAN solar thermal Power Tower plant. Renew. Energy 2012, 43, 18-29. [CrossRef]

12. Amadei, C.A.; Allesina, G.; Tartarini, P.; Yuting, W. Simulation of GEMASOLAR-based Solar Tower plants for the Chinese energy market: In fluence of plant downsizing and location change. Renew. Energy 2013, 55, 366-373. [CrossRef]

13. Hanrieder, N.; Wilbert, S.; Mancera-Guevara, D.; Buck, R.; Giuliano, S.; Pitz-Paal, R. Atmospheric extinction in solar tower plants-A review. Sol. Energy 2017, 152, 193-207. [CrossRef]

14. Casati, E.; Casella, F.; Colonna, P. ScienceDirect Design of CSP plants with optimally operated thermal storage. Sol. Energy 2015, 116, 371-387. [CrossRef]

15. System Advisor Model Version 2017.9.5 (SAM 2017.9.5); National Renewable Energy Laboratory: Golden, CO, USA. Available online: https://sam.nrel.gov/content/downloads (accessed on 12 October 2019).

16. Zhang, H.L.; Baeyens, H.L.; Degreve, J.; Caceres, G. Concentrated solar power plants: Review and design methodology. Renew. Sustain. Energy Rev. 2013, 22, 466-481. [CrossRef]

17. Stine, W.B.; Harrigan, R.W. Solar Energy Systems Design; John Wiley and Sons, Inc: New York, NY, USA, 1986.

18. Wagner, M.J.; Wendelin, T. Solar Pilot: A Power Tower Solar field layout and characterization tool. Sol. Energy 2018, 171, 185-196. [CrossRef]

19. National Renewable Energy Laboratory (NREL). Power Tower Projects. Available online: www.nrel.gov/csp/ solarpaces/power_Tower.cfm (accessed on 9 November 2017).

20. Boretti, A.; Castelletto, S.; Al-zubaidy, S. Concentrating solar Power Tower technology: Present status and outlook. Nonlinear Eng. 2019, 8, 10-31. [CrossRef]

(C) 2019 by the author. Licensee MDPI, Basel, Switzerland. This article is an open access article distributed under the terms and conditions of the Creative Commons Attribution (CC BY) license (http://creativecommons.org/licenses/by/4.0/). 